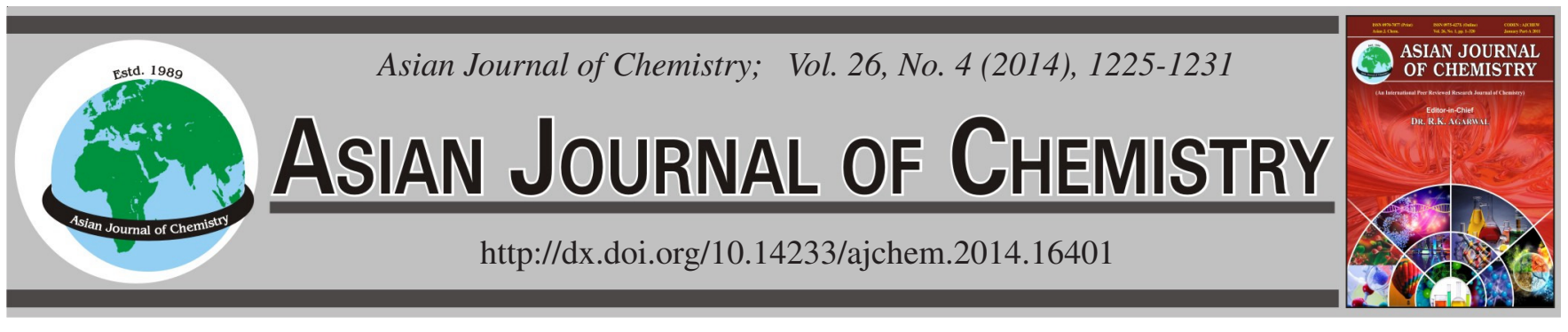

\title{
Antioxidant and Antifungal Activities of Some Agro Wastes and Their Phenolic Acid Profile
}

\author{
Rehana Naseer, Bushra Sultana*, Haq Nawaz Bhatti and Amer Jamil
}

Department of Chemistry and Biochemistry, University of Agriculture, Faisalabad-38040, Pakistan

*Corresponding author: E-mail: bushrasultana2005@yahoo.com

\begin{abstract}
In present study some selected agro wastes extracted with different solvent i.e. methanol, ethanol, chloroform and acetone were investigated for their antifungal and antioxidant activities and phenolic acid profile. The tested waste materials contained appreciable amount of total phenolic (0.27-198.90 GAE mg/g DW) and total flavonoids (0.02-96.20 CE mg/g DW), DPPH scavenging capacity (25.23-75.65 \%), reducing power as $0.342 .-1.74$ (at $10 \mathrm{mg} / \mathrm{mL}$ extract concentration, absorbance at $\lambda=700 \mathrm{~nm}$ ) and percent inhibition of linoleic acid (43.23-82.34\%). Antifungal activity of selected agro wastes extracts was assessed by using disc diffusion method and MIC against Aspergillus flavus and Aspergillus parasiticus strains. Citrus leaves and pomegranate peel extract showed remarkable antifungal activity compared to other extracts with the maximum zone of inhibition 37 and $35 \mathrm{~mm}$, respectively. In addition, GC/MS analysis showed the presence of seven different phenolic acids i.e., gallic acid, $p$-coumaric acid, caffeic acid, ferulic acid, protocacheuic acid, cinamic acid and vanillic acid.
\end{abstract}

Keywords: Agro wastes, Aspergilllus, Antifungal activity, GC/MS analysis, Antioxidant potential.

\section{INTRODUCTION}

Agro-industrial wastes are rich source of many important bioactive compounds, so their potential use in food industry as natural antioxidant and antimicrobial agents may be a good approach to replace synthetic preservatives. However, it may also solve the environmental problems concerning disposal of wastes and their by-products and can be a source of profit for peoples living in industrial areas ${ }^{1}$.

Recent research reports reveal that phytophenols are the most abundant secondary metabolites which are found in plants with more than 8,000 structures. They may be of simple structures like phenolic acids and complex compounds like tannins ${ }^{2}$. Wide spectrums of biological activities like antioxidant, antimicrobial, antiallergenic, anti-inflammatory, antithrombotic, anti-orthrogenic have been accredited to phenolic compounds ${ }^{3}$.

Many studies revealed the inhibitory potential of phenolics on fungal growth ${ }^{4,5}$. Kim et al. ${ }^{6}$ demonstrated that phenolics such as vanillyl acetone, salicylic acid, vanillin, thymol and cinnamic acid may cause inhibition of $A$. flavus growth by defense system of targeting the mitochondrial oxidative stress.

At present research has focused to investigate some new antimicrobial compounds which show diverse chemical structures and better mechanisms of action ${ }^{7}$. Natural plant products may successfully replace synthetic chemicals and provide an alternative safe mode to protect food commodities as well as other agricultural crops of nutritional significance from development and growth of fungi i.e., A. flavus and $A$. parasiticus as well as oxidative deterioration. Many studies have confirmed the presence of bioactive compounds having good antimicrobial potential in lemon peels ${ }^{8}$, pomegranate peels ${ }^{9}$ and grape seeds ${ }^{10}$.

A huge amount of wastes including mango peel, citrus peel and onion peel, garlic peel, pomegranate peel citrus and leave is produced at industrial and home level, disposal of which creates an environmental problem. It is well known that the peel and seed fractions of some vegetables and fruits have higher bioactivities components than other fractions ${ }^{11,12}$. However, a limited number of agro-wastes have been investigated for their phenolic profiles. Therefore, in the present research project characterization of active phenolic acids that can act as antifungal, antioxidant, anti-inflammatory and antibacterial agents was established by gas chromatography mass spectrometry.

The objective of present research was to study the antimicrobial and antioxidant properties of some locally producing wastes against food borne pathogens so as to reduce economic loss of cereals and food commodities by oxidation and fungal contamination.

\section{EXPERIMENTAL}

Lemon peel (Citrus limon), pomegranate peel (Punica grantum L.), mango peel (Mangiferaindica L.), mango kernel 
(Mangiferaindica L.), lemon leaves (Citrus limon), garlic leaves (Allium sativum L.) and onion leaves (Allium cepa L.) were collected from local agricultural resources of Faisalabad, Pakistan. After washing with tap water sample were subjected to air drying.

2,2,-Diphenyl-1-picrylhydrazyl, folin-ciocalteu reagent, gallic acid, ascorbic acid, trichloro-acetic acid, aluminum chloride, sodium nitrite, ammonium thiocyanate, feric chloride, potassium fericyanate and ferous chloride were purchased from Sigma Chemical Co. (St Louis, MO, USA) and standards of phenolic acids (caffeic acid, $p$-coumaric acid, vanillic acid, ferulic acid, cinamic acid, protocacheuic and gallic acid). All other chemicals were of analytical grade i.e., chloroform, ehtyalacetate, methanol, $\mathrm{HCl}$, bis(trimethylsilyl) trifluoroacetamide (BSTFA), tertiary butyl hydroxytoluene (TBHQ), butylatedhydroxytoluene (BHT) trimethychlorosilane (TMCS) used in this study were purchased from merck (Darmstadt, Germany). Potato dextrose agar (PDA) culture media and discs of antibiotic standard were obtained from Oxoid Ltd., (Hampshire, UK).

Extraction of antioxidant/antifungal components: Antifungal and antioxidant components from dried samples were extracted by using different solvents i.e. methanol, ethanol, chloroform and acetone. The extraction of powdered sample $(20 \mathrm{~g})$ of 80 mesh size was done at room temperature in an orbital shaker (Gallenkamp, UK) with $200 \mathrm{~mL}$ solvent for overnight. Supernatant and sediments were parted by filtration with Wattman no. 1 filter paper and separated residue was extracted (two time) with respective solvent and filtered then combine filtrate. Solvent was evaporated at $45{ }^{\circ} \mathrm{C}$ under reduced pressure, using a rotary evaporator (N-N Series, Eyela, Rikakikai Co. Ltd, Tokyo, Japan) and the yield of nearly dried extract was calculated. The dried extracts were stored at $4{ }^{\circ} \mathrm{C}$, till further used.

Estimation of total phenolic contents (TPCs): The total phenolic contents of wastes extracts were estimated according the procedure of Chaovanalikit and Wrolstad ${ }^{13}$, using FolinCiocalteu reagent. Briefly, extract $(50 \mathrm{mg}$ ) was added in Folinciocalteu reagent $(0.5 \mathrm{~mL})$ and deionized water $(7.5 \mathrm{~mL})$. Then incubate at room temperature $(10 \mathrm{~min})$ and add $20 \% \mathrm{w} / \mathrm{v}$ sodium carbonate solution $(1.5 \mathrm{~mL})$ and heat mixture for 20 min at $40{ }^{\circ} \mathrm{C}$ in water bath then cooled by icing. Absorbance was taken at $755 \mathrm{~nm}$ with spectrophotometer (U-2001, Hitachi Instruments Inc., Tokyo, Japan). To calculate amount of TPs calibration curve of Gallic acid at concentration range of 10$100 \mathrm{ppm}\left(\mathrm{R}^{2}=0.9986\right)$ was used and unit to express results was Gallic acid equivalents (GAE) g/100 g of dry plant matter. Results were expressed by taking average.

Estimation of total flavonoid contents (TFCs): The amount of total flavonoid contents was assessed according to well established spectrophotometric procedure ${ }^{14}$. Briefly, $1 \mathrm{~mL}$ of waste extract $(0.1 \mathrm{mg} / \mathrm{mL})$ was added in a $10 \mathrm{~mL}$ volumetric flask containing $4 \mathrm{~mL}$ water.Then added $0.3 \mathrm{~mL} \mathrm{NaNO}_{2}(5$ $\%$ solution) keep for $5 \mathrm{~min}$, then $0.3 \mathrm{~mL}$ of $10 \%$ solution of $\mathrm{AlCl}_{3}$ was added; after next $6 \mathrm{~min}$, add $2 \mathrm{~mL}$ of $1 \mathrm{M} \mathrm{NaOH}$. Then add water $(2.4 \mathrm{~mL})$, mixed thoroughly and absorbance noted at $510 \mathrm{~nm}$. Total flavonoid contents were presented as catechin equivalents (g/100 g of dry plant matter). Each sample was analyzed three times and averaged.
DPPH' scavenging assay: 2,2'-Diphenyl-1-picryl-hydrazyl (DPPH) free radical scavenging activity of crude extracts was evaluated by following previous adopted procedure ${ }^{15}$. Briefly, add $1 \mathrm{~mL}$ of extract $(25 \mu \mathrm{g} / \mathrm{mL}$ of dry matter in methanol) in DPPH solution that was freshly prepared at concentration 0.025 $\mathrm{g} / \mathrm{L}$ and absorbance was taken at $515 \mathrm{~nm}$ after $0,0.5,1,2,5$ and $10 \mathrm{~min}$ using a spectrophotometer. The un-scavenged DPPH radical (DPPH ${ }^{\circ}$ ) was estimated from calibration curve and comparison was made between the radical scavenging activities of various extracts by using absorbance value taken at 5 th $\min$.

Antioxidant activity (linoleic acid system): Antioxidant activity of different agriculture waste extracts was also evaluated by the oxidation of linoleic acid system ${ }^{15}$. Accurately weighed $5 \mathrm{mg}$ extract was mixed with linoleic acid $(0.13 \mathrm{~mL})$, $99.8 \%$ ethanol $(10 \mathrm{~mL})$ and $0.2 \mathrm{M}$ sodium phosphate buffer $(10 \mathrm{~mL})$ of $\mathrm{pH} 7$ in a $25 \mathrm{~mL}$ of volumetric flask. The volume was made up with distilled water and incubated for $360 \mathrm{~h}$ at $40{ }^{\circ} \mathrm{C}$. From peroxide value extent of oxidation of linoleic acid was estimated using earlier reported thiocyanate protocol $^{16}$. According to this $10 \mathrm{~mL}$ of ethanol (75\% v/v), 0.2 $\mathrm{mL}$ of ammonium thiocyanate solution (30\% w/v in water), $0.2 \mathrm{~mL}$ of sample solution and $0.2 \mathrm{~mL}$ of ferrous chloride $\left(\mathrm{FeCl}_{2}\right)$ solution $(20 \mathrm{mM}$ in $3.5 \% \mathrm{HCl}$; v/v) was added sequentially and mixed for $3 \mathrm{~min}$. Absorption was noted at $500 \mathrm{~nm}$ by spectrophotometer (U-2001, Hitachi Instruments Inc., Tokyo, Japan). Control contained all reagents except sample and butylatedhydroxytoluene (BHT) synthetic antioxidant was taken as positive control. Percent inhibition of linoleic acid oxidation was estimated by using the formula given below:

$100-[($ Abs. increase of sample at $360 \mathrm{~h} / \mathrm{Abs}$. increase of control at $360 \mathrm{~h}) \times 100$ ]

Determination of reducing power: The antioxidant potential of different waste materials was also investigated by measuring their reducing power following a reported of Yen et al. ${ }^{16}$, with some amendments. Concentrated extract (2.5-10 $\mathrm{mg}$ ) was added ina $5 \mathrm{~mL}$ sodium phosphate buffer of $\mathrm{pH} 6.6$ $(0.2 \mathrm{M})$ and $5.0 \mathrm{~mL}$ of potassium ferricyanide $(1 \%)$; then heating of mixture was done at $50{ }^{\circ} \mathrm{C}$ for $20 \mathrm{~min}$. Then add 5 $\mathrm{mL}$ of trichloroacetic acid (10\%) and then centrifuged at $980 \mathrm{~g}$ at $5^{\circ} \mathrm{C}$ in a refrigerated centrifugefor $10 \mathrm{~min}$ (CHM-17; Kokusan Denki, Tokyo, Japan). From upper layer $5 \mathrm{~mL}$ of mixture was taken and added $5 \mathrm{~mL}$ of water following $1 \mathrm{~mL}$ of ferric chloride $(0.1 \%)$ solution and absorbance was noted at 700 $\mathrm{nm}$ by spectrophotometer (U-2001, Hitachi Instruments Inc., Tokyo, Japan). Three analysis were performed at each sample and results were averaged.

Fungal strains: The pure strains of A. flavus and A. parasitic were obtained from National Institute for Biotechnology and Genetic Engineering (NIBGI),Faisalabad, Pakistan. Strains were cultured at potato dextrose agar (PDA) (Oxoid, UK) at $28{ }^{\circ} \mathrm{C}$ for overnight and maintained at $4{ }^{\circ} \mathrm{C}$.

Disc diffusion method: Antifungal activity of waste extracts was tested by disc diffusion method ${ }^{17}$ with slight modifications. The autoclaved PDA medium was transferred in sterilized petri dishes and was inoculated with particular test fungi. The media was allowed to solidify then paper discs of $6 \mathrm{~mm}$ in diameter containing $50 \mu \mathrm{L}$ ofwaste extract were placed at PDA surface. As positive reference flumequine was used whereas for 
negative control disc without sample extract was used. The plates were placed in incubator $\left(28^{\circ} \mathrm{C}\right)$ for $48 \mathrm{~h}$ and inhibitory zones $(\mathrm{mm})$ were measured by zone reader.

Minimum inhibitory concentration (MIC): Antifungal activity of waste extracts was also assessed by measuring minimum inhibitory concentration (MIC) following the method of Misra and Dixit ${ }^{18}$, with slight modification. A serial dilution of extract (10-100 $\mu \mathrm{g} / \mathrm{mL})$ was made in microplate with one growth control. SDB $(160 \mathrm{uL})$ was added on to the microplate with $20 \mu \mathrm{L}$ of tested solution. Then $20 \mathrm{uL}$ culture of $5 \times 10^{5}$ $\mathrm{CFU} / \mathrm{mL}$ of the A. flavus and A. parasiticus was poured on to the separate micro plate. The plates were kept in incubator for $24 \mathrm{~h}$ at $28^{\circ} \mathrm{C}$ and then to stop the growth in controls plates were transferred at $22{ }^{\circ} \mathrm{C}$. By micro titer plate reader optical density was measured at $620 \mathrm{~nm}$ and MICs were calculated.

Extraction and derivatizationof phenolic acids for GC/MS analysis: Phenolic acids were extracted/hydrolyzed and derivatized according to the adopted procedure of Tokusoglu et al. ${ }^{19} .25 \mathrm{~mL}$ acidified methanol containing $\mathrm{HCl}$ $(1 \% \mathrm{v} / \mathrm{v})$ and TBHQ $(0.5 \mathrm{mg} / \mathrm{mL})$ was added in $5 \mathrm{~g}$ plant material along with $5 \mathrm{~mL}$ of $\mathrm{HCl}(1.2 \mathrm{M}$,) and refluxed for $2 \mathrm{~h}$ with carefully stirring. Then cooled mixture to room temperature and centrifuged at $5000 \mathrm{rpm}$ for $10 \mathrm{~min}$. Separate upper layer and to remove air bubbles mixture was sonicated for $5 \mathrm{~min}$.

Phenolic acids were further extracted with ethyl acetate $(1: 1, \mathrm{v} / \mathrm{v})$ and fraction obtained from extraction was treated with $\mathrm{NaHCO}_{3}(0.5 \mathrm{M})(1: 1, \mathrm{v} / \mathrm{v})$ for three times and evaporation was done under nitrogen flow. The dried extract was dissolved in ethyl acetate and solution was again dried by $\mathrm{Na}_{2} \mathrm{SO}_{4}$ for $5 \mathrm{~min}$. For silation dried solution $(400 \mu \mathrm{L})$ was transferred to a vial and added $100 \mu \mathrm{L}$ bis(trimethylsilyl) trifluoroacetamide (BSTFA) $+1 \%$ trimethychlorosilane (TMCS). The vial was heated in water bath at $70{ }^{\circ} \mathrm{C}$ for $15 \mathrm{~min}$. From the silylated mixture $1 \mu \mathrm{L}$ was analyzed by GC-MS.

Gas chromatography-mass spectrometry (GC-MS): The GC/MS used to analyze silylated samples was Shimadzu gas chromatograph (GC/MS (6890N) Agilent-Technologies, California, USA) coupled to the Shimadzu mass spectrometer (QP 2010 PLus). Separation occurred in HP-5MS, fused silica capillary column $(30 \mathrm{~m} \times 0.25 \mathrm{~mm}, 0.25 \mu \mathrm{m})$ with the injection volume of $1 \mu \mathrm{L}$ in a "split" mode (split ratio, 1: 100) and Helium $(p=100 \mathrm{kPa})$ was used as carrier gas. The temperature of injector (auto injector) was set $250^{\circ} \mathrm{C}$, oven was $280^{\circ} \mathrm{C}$, interface was $280{ }^{\circ} \mathrm{C}$ and detector (scanning mode) was operated at 50-550 $\mathrm{m} / \mathrm{z} @ 1.5 \mathrm{scan} / \mathrm{sec}$. The integration of GC-MS system was carried out using lab solutions-GC-MS software. Phenolic acids were identified by comparing their retention time with those of authentic compound that were eluted under same conditions and with spectral data obtained from Wiley 8 library.

Statistical analysis: The three different samples of each agro waste were assayed. All the measurements were made in triplicate and the results were reported as mean $(n=3 \times 3) \pm$ $\mathrm{SD}(\mathrm{n}=3 \times 3)$. Two way analysis of variance ANOVA was performed to analyze the data using Minitab 2000 versions 13,2, Statistical software (Minitab Inc. Pennysalvania, USA) at $5 \%$ significance level.

\section{RESULTS AND DISCUSSION}

The yields of antioxidant and antifungal componentsextracted from various waste materials using different solvents are presented in Table-1. Among different extraction solvents used in present study methanol showed highest yield ranged from 12.30 to $57.71 \%$ followed by ethanol (11.69 -52.69\%), acetone (10.21-25.35\%) and chloroform (7.11-11.39\%). The highest extract yield $(57.71 \%)$ was achieved with absolute methanol from pomegranate peels while lowest was obtained (7.11\%) by chloroform from citrus peel. Results showed that there was a significant difference $(\mathrm{P}<0.05)$ among the yields obtained from different wastes with the different solvent. The highest extract yield $(57.71 \%)$ from pomegranate peels and mango peel $32.22 \%$ as found in our present study were found somewhat higher than those investigated by Sultana et al. ${ }^{20}$. They reported $29.9 \%$ yield for pomegranate peel, $24.6 \%$ for banana peel, $21.5 \%$ for citrus peel and $16.4 \%$ for apple peel with $80 \%$ methanol. Differences in yields obtained from different agro wastes with various solvents depend on availability of different extractable component, nature of soil and agroclimatic conditions ${ }^{21}$. According to our results methanol and ethanol exhibited highest yield compared to acetone and chloroform. Methanol is usually recommended to be a better solvent for the extraction of antioxidant compounds because of polarity and availability. The effectiveness and ability of methanol may increase using water as a co solvent especially when extraction of antioxidants of various kinds is required ${ }^{15}$.

Total phenolic and total flavonoid contents: The total phenolic and total flavonoid contents investigated for different agro waste using different solvents are shown in Table-2. The interest in the phenolics has increased outstandingly due to their prominent free radical scavenging activity ${ }^{22}$ therefore mostly total phenolic assay is used to assess the antioxidant potential of plant extracts. Many researchers demonstrated a well established correlation between antioxidant activity and phenolic profile ${ }^{23}$.

TABLE-1

EXTRACT YIELD (g/100 g DW) OF VARIOUS AGRO WASTES

\begin{tabular}{|c|c|c|c|c|}
\hline Plant used & Methanol & Ethanol & Chloroform & Acetone \\
\hline Mango peel & $32.22 \pm 0.67_{\mathrm{d}}^{\mathrm{c}}$ & $25.51 \pm 0.51_{c}^{b}$ & $11.10 \pm 0.23_{\mathrm{a}}^{\mathrm{c}}$ & $21.93 \pm 0.45_{\mathrm{c}}^{\mathrm{d}}$ \\
\hline Pomegranate peel & $50.71 \pm 1.10_{\mathrm{d}}^{\mathrm{d}}$ & $57.69 \pm 1.32_{\mathrm{d}}^{\mathrm{d}}$ & $11.39 \pm 0.22^{{ }^{c}}{ }^{\mathrm{c}}$ & $25.35 \pm 0.61_{b}{ }^{d}$ \\
\hline Citrus peel & $14.92 \pm 0.29{ }_{c}{ }^{a}$ & $19.40 \pm 0.43_{\mathrm{d}}{ }^{\mathrm{a}}$ & $7.11 \pm 0.15_{\mathrm{a}}^{\mathrm{b}}$ & $11.50 \pm 0.23_{b}{ }^{b}$ \\
\hline Citrus leaves & $23.16 \pm 0.46_{d}{ }^{b}$ & $20.81 \pm 0.42_{\mathrm{d}}^{\mathrm{a}}$ & $11.60 \pm 0.24_{\mathrm{a}}^{\mathrm{d}}$ & $19.21 \pm 0.41_{c}{ }^{c}$ \\
\hline Onion leaves & $15.20 \pm 0.32_{\mathrm{d}}^{\mathrm{a}}$ & $16.20 \pm 0.33_{\mathrm{d}}{ }^{\mathrm{a}}$ & $8.21 \pm 0.14_{a^{b}}^{b}$ & $12.91 \pm 0.27_{c}^{b}$ \\
\hline Garlic leaves & $12.30 \pm 0.26_{\mathrm{d}}^{\mathrm{a}}$ & $11.69 \pm 0.25_{c}{ }^{a}$ & $8.42 \pm 0.17_{\mathrm{a}}^{\mathrm{b}}$ & $10.21 \pm 0.21_{b}{ }^{a}$ \\
\hline Mango kernel & $27.65 \pm 0.51_{d}^{b}$ & $25.35 \pm 0.53_{\mathrm{d}}^{\mathrm{b}}$ & $10.61 \pm 0.23^{{ }^{c}}$ & $13.65 \pm 0.27 \mathrm{a}^{\mathrm{b}}$ \\
\hline
\end{tabular}

Values are mean \pm SD of all samples analyzed individually in triplicate $(P<0.05)$. 
TABLE-2

TOTAL PHENOLICS (GAE mg/g DW) AND FLAVONOID (CE mg/g DW) CONTENTS OF VARIOUS AGRO WASTES

\begin{tabular}{|c|c|c|c|c|c|c|c|c|}
\hline \multirow{2}{*}{ Plant used } & \multicolumn{4}{|c|}{ Total phenol contents } & \multicolumn{4}{|c|}{ Total flavonoid contents } \\
\hline & Methanol & Ethanol & Chloroform & Acetone & Methanol & Ethanol & Chloroform & Acetone \\
\hline Man & $116.80 \pm 2.10_{\mathrm{d}}^{\mathrm{c}}$ & $122.60 \pm 2.59_{\mathrm{d}}^{\mathrm{c}}$ & $14.34 \pm 0.29_{\mathrm{a}}^{\mathrm{c}}$ & $31.41 \pm 0.74^{\mathrm{b}}$ & $90.89 \pm 1.74_{d}^{d}$ & $93.12 \pm 2.00_{d}^{d}$ & $6.64 \pm 0.14_{\mathrm{a}}^{\mathrm{b}}$ & $11.76 \pm 0.20_{\mathrm{a}}^{\mathrm{b}}$ \\
\hline Pom & $198.90 \pm 3.92_{\mathrm{d}}^{\mathrm{d}}$ & $193.20 \pm 3.15_{d}^{d}$ & $24.43 \pm 0.49^{d \mathrm{a}}$ & $60.91 \pm 1.31_{\mathrm{b}}{ }^{\mathrm{c}}$ & $96.20 \pm 1.199^{d}$ & $83.91 \pm 0.17_{\mathrm{d}^{\mathrm{d}}}$ & $14.69 \pm 0.29^{d}$ & $39.61 \pm 0.78_{b}{ }^{\mathrm{d}}$ \\
\hline Citrus peel & $158.79 \pm 1.61_{d}{ }^{d}$ & $163.26 \pm 3.00_{\mathrm{d}}^{\mathrm{d}}$ & $18.61 \pm 0.39_{a}^{\mathrm{c}}{ }^{\mathrm{c}}$ & $43.71 \pm 0.94_{b^{b}}{ }^{b}$ & $25.33 \pm 0.48_{\mathrm{d}}^{\mathrm{b}}$ & $28.67 \pm 0.69_{d}^{b}$ & $9.32 \pm 0.19{ }_{a^{c}}^{c}$ & $12.49 \pm 0.21_{\mathrm{a}}{ }^{\mathrm{b}}$ \\
\hline Citrus & $192.41 \pm 2.99_{\mathrm{d}}^{\mathrm{d}}$ & $169.16 \pm 2.92_{\mathrm{d}}{ }^{\mathrm{d}}$ & $21.62 \pm 0.41_{a}{ }^{d}$ & $59.23 \pm 1.21_{\mathrm{a}}{ }^{\mathrm{C}}$ & $31.34 \pm 0.65_{\mathrm{d}}^{\mathrm{b}}$ & $21.02 \pm 0.51_{\mathrm{b}}{ }^{\mathrm{a}}$ & $10.27 \pm 0.22^{\mathrm{a}}{ }^{\mathrm{c}}$ & $14.36 \pm 0.29^{\mathrm{b}}$ \\
\hline Onio & $12.85 \pm 0.29 \mathrm{c}^{\mathrm{a}}$ & $16.12 \pm 0.32_{\mathrm{d}^{\mathrm{a}}}$ & $7.26 \pm 0.17_{\mathrm{a}}^{\mathrm{b}}$ & $12.56 \pm 0.29 \mathrm{c}^{\mathrm{a}}$ & $5.61 \pm 0.11_{c}{ }^{a}$ & $8.12 \pm 0.17_{\mathrm{d}}^{\mathrm{a}}$ & $2.96 \pm 0.04_{a}^{a}$ & $4.67 \pm 0.08^{a}{ }^{a}$ \\
\hline Garlic & $6.97 \pm 0.13_{\mathrm{d}}^{\mathrm{a}}$ & $4.81 \pm 0.08_{\mathrm{b}}{ }^{\mathrm{a}}$ & $3.52 \pm 0.06_{a}^{a}{ }^{a}$ & $6.10 \pm 0.14_{d}^{a}$ & $4.10 \pm 0.08_{\mathrm{d}}^{\mathrm{a}}$ & $3.85 \pm 0.06_{\mathrm{d}}^{\mathrm{a}}$ & $2.13 \pm 0.03_{\mathrm{a}}^{\mathrm{a}}$ & $3.16 \pm 0.05_{\mathrm{b}}{ }^{\mathrm{a}}$ \\
\hline Mango kernel & $63.89 \pm 1.32_{\mathrm{d}}^{\mathrm{b}}$ & $69.24 \pm 1.24_{\mathrm{d}}^{\mathrm{b}}$ & $9.61 \pm 0.17 \mathrm{a}^{\mathrm{b}}$ & $19.52 \pm 0.399^{\mathrm{a}}$ & $45.56 \pm 0.90_{\mathrm{d}}^{\mathrm{b}}$ & $32.62 \pm 0.72^{\mathrm{b}}{ }^{\mathrm{b}}$ & $3.96 \pm 0.07_{\mathrm{a}}^{\mathrm{b}}$ & $6.76 \pm 0.13^{a}{ }^{a}$ \\
\hline
\end{tabular}

Values are mean \pm SD of all samples analyzed individually in triplicate $(P<0.05)$.

Results showed that methanolic and ethanolic extract showed good level of TPCs and TFCs followed by acetone however, chloroform extract showed least amount. This is in agreement with the findings of Sidhuraju and Becker ${ }^{24}$ who reported that methanol and ethanol are efficient solvent to extract antioxidant compounds. According to data TPCs of different agro waste extracts varied significantly $(\mathrm{P}<0.05)$ (6.97-198.90 GAE mg/g DW) in methanol, (4.81-193.20 GAE $\mathrm{mg} / \mathrm{g}$ DW) ethanol, (6.10 to $60.91 \mathrm{GAE} \mathrm{mg} / \mathrm{g} \mathrm{DW}$ ) acetone and in chloroform (3.52- 24.43 GAE mg/g DW). However amounts of TPCs assessed for methanolic and ethanolic extracts were found to be significantly higher $(\mathrm{P}<0.05)$ than for acetone and chloroform extracts.

Among the various investigated agro wastes, extracts of fruits peels were found to contain relatively higher contents of TP and TF. Our findings correlate with the report of Li et al. ${ }^{25}$ that a higher amount of antioxidants like phenolics, anthocynins and flavonol present in peels. In present study a remarkable high amount of TPs for methanolic pomegranate peel extract (198.90 GAE mg/g DW) was found to be higher than previously reported for aqueous pomegranate peel extract $(161.25 \mathrm{GAE}$ $\mathrm{mg} / \mathrm{g})^{26}$ while citrus peel (163.26 GAE mg/g DW) and mango peels (116.80 GAE mg/g DW) were found comparable to those reported earlier for citrus sinesus var. Navel peel (160.3 GAE $\mathrm{mg} / \mathrm{g})^{27}$ and for mango peels (54.67-109.70 GAE mg/g) ${ }^{3}$. Where as among the leaves highest level of TPC was observed in citrus leaves (192.41 GAE mg/g DW) while lowest in garlic leaves (6.97 GAE mg/g).

The amount of total flavonoids among different waste extracts varied significantly $(\mathrm{P}<0.05)$ ranging 4.10-96.20 CE $\mathrm{mg} / \mathrm{g} \mathrm{DW}$ in methanol, 3.85-83.91 CE mg/g DW in ethanol, 3.16 to $39.61 \mathrm{CE} \mathrm{mg/g} \mathrm{DW} \mathrm{in} \mathrm{acetone} \mathrm{and} \mathrm{2.13-14.69} \mathrm{CE} \mathrm{mg/}$ g DW in chloroform (Table-2). The remarkable high amounts of total flavonoids in pomegranate peel $(96.20 \mathrm{mg} / \mathrm{g} \mathrm{CE})$ and mango peel extracts $(93.12 \mathrm{mg} / \mathrm{g} \mathrm{CE})$ were found to be significantly higher $(\mathrm{P}<0.05)$ than those reported earlier by Kanatt et al ${ }^{26}$ for pomegranate peel extract $(7.57 \mathrm{mg} / \mathrm{g} \mathrm{CE})$ and Dabrosca et al. ${ }^{28}$ for limonella apple peel $(47.80 \mathrm{mg} / 100$ g). The type of plant part, nature of soil, growing stages, maturity at the stage of harvest and application of different treatments at post-harvest level may affect the presence and amount of phenolics and flavonoids in plant. Moreover, the difference in gene expression in different parts of a plant would cause to affect the process of synthesis and accumulation ofdifferent components at different ratio or different ratio of same component which actually reflects antioxidant potential and other biological activities of plant $\mathrm{t}^{29}$.

DPPH radical scavenging assay: The DPPH radical has been extensively applied method to assess the antioxidant potential of food items, such as vegetables, olive oils, fruits, juices and wines etc.The antioxidant efficacy of a plant material can be accessed from its potential to donate hydrogen to DPPH free radical which in turn changes to stable diamagnetic molecule $^{30}$. Its high sensitivity for active ingredients enable it to accommodate a large number of samples in a very short time even at low concentration, this has increased its use for measuring radical scavenging activity of different plant extracts ${ }^{31}$.

The DPPH radical scavenging activities of various investigated agro waste extracts in different solvents are shown in Table-3. The potential of different wastes extracts to scavenge free radical varied $31.92-75.65 \%$ in methanol, $34.45-71.24 \%$ in ethanol, 29.76-67.31\% in acetone and $25.23-50.51 \%$ in chloroform. All the investigated plants showed appreciable range to scavenge free radical however, highest efficacy was exhibited by pomegranate peel (50.51-75.65 \%) followed by citrus leaves (45.11-64.38\%), citrus peel (44.72-57.23\%), onion leaves (42.64-57.37\%) garlic leaves (39.22-54.83\%) mango peel (41.42-46.56\%) and mango kernel (25.23-31.92\%).

\begin{tabular}{|c|c|c|c|c|c|c|c|c|}
\hline \multirow{3}{*}{ Plant used } & \multicolumn{6}{|c|}{$\begin{array}{l}\text { TABLE-3 } \\
\text { DPPH RADICAL SCAVENGING ACTIVITY (\%) AND INHIBITION OF } \\
\text { LINOLEIC ACID OXIDATION }(\%) \text { OF VARIOUS AGRO WASTES }\end{array}$} & & \\
\hline & \multicolumn{4}{|c|}{ DPPH radical scavenging activity (\%) } & \multicolumn{4}{|c|}{ Inhibition of linoleic acid oxidation (\%) } \\
\hline & Methanol & Ethanol & Chloroform & Acetone & Methanol & Ethanol & Chloroform & Acetone \\
\hline Mango peel & $46.56 \pm 1.12^{\mathrm{b}}{ }^{\mathrm{b}}$ & $52.52 \pm 1.02{ }_{\mathrm{d}}^{\mathrm{c}}$ & $41.42 \pm 0.93_{\mathrm{a}}^{\mathrm{c}}$ & $43.21 \pm 0.93_{\mathrm{a}}^{\mathrm{b}}$ & $62.23 \pm 1.22_{\mathrm{c}}^{\mathrm{b}}$ & $66.66 \pm 1.38_{\mathrm{d}}^{\mathrm{c}}$ & $58.92 \pm 1.12_{\mathrm{a}}^{\mathrm{c}}$ & $61.76 \pm 1.28_{\mathrm{b}}^{\mathrm{c}}$ \\
\hline Pomegranate & $75.65 \pm 1.52_{d}{ }^{d}$ & $71.24 \pm 1.43_{\mathrm{d}}^{\mathrm{d}}$ & $50.51 \pm 0.12^{\mathrm{a}}{ }^{\mathrm{d}}$ & $67.31 \pm 1.21_{c}{ }^{d}$ & $82.34 \pm 1.73_{d}{ }^{d}$ & $79.87 \pm 1.42_{\mathrm{d}}^{\mathrm{d}}$ & $66.21 \pm 1.15_{\mathrm{a}}^{\mathrm{d}}$ & $75.98 \pm 1.39_{c}{ }^{d}$ \\
\hline Citrus peel & $57.23 \pm 1.25_{\mathrm{d}}^{\mathrm{C}}$ & $60.61 \pm 1.29_{\mathrm{d}}^{\mathrm{c}}$ & $44.72 \pm 0.92_{\mathrm{a}}{ }^{\mathrm{d}}$ & $54.46 \pm 1.03_{\mathrm{c}}^{\mathrm{c}}$ & $73.81 \pm 1.37_{d}^{d}$ & $70.71 \pm 1.38_{c}{ }^{d}$ & $61.42 \pm 1.20_{\mathrm{a}}^{\mathrm{d}}$ & $66.54 \pm 1.30_{\mathrm{b}}^{\mathrm{c}}{ }^{\mathrm{c}}$ \\
\hline Citrus leaves & $64.38 \pm 1.48_{\mathrm{d}}^{\mathrm{c}}$ & $62.62 \pm 1.21_{\mathrm{d}}^{\mathrm{d}}$ & $45.11 \pm 0.93^{a}{ }^{d}$ & $59.97 \pm 1.14_{d}{ }^{d}$ & $76.21 \pm 1.47_{d}^{d}$ & $73.16 \pm 1.51_{c}{ }^{d}$ & $64.13 \pm 0.71_{\mathrm{a}}^{\mathrm{d}}$ & $69.41 \pm 1.25_{\mathrm{b}}{ }^{\mathrm{d}}$ \\
\hline Onion leaves & $57.37 \pm 1.23_{\mathrm{d}}^{\mathrm{c}}$ & $61.13 \pm 2.10_{\mathrm{d}}^{\mathrm{c}}$ & $42.64 \pm 0.88_{a}{ }^{c}$ & $53.34 \pm 1.12_{\mathrm{c}}^{\mathrm{c}}$ & $55.13 \pm 1.09_{\mathrm{d}}^{\mathrm{b}}$ & $50.54 \pm 1.06_{\mathrm{c}}^{\mathrm{a}}$ & $43.23 \pm 1.05_{a^{a}}^{a}$ & $47.45 \pm 0.94_{b}{ }^{a}$ \\
\hline Garlic leaves & $54.83 \pm 1.54_{\mathrm{d}}{ }^{\mathrm{c}}$ & $50.54 \pm 1.90_{c}^{c}$ & $39.22 \pm 0.83_{a^{c}}{ }^{c}$ & $44.47 \pm 0.94_{b}{ }^{b}$ & $67.04 \pm 1.32_{\mathrm{d}}^{\mathrm{c}}$ & $65.78 \pm 1.31_{d}{ }^{c}$ & $52.01 \pm 1.21_{\mathrm{a}}^{\mathrm{b}}$ & $55.32 \pm 1.03_{\mathrm{b}}^{\mathrm{b}}$ \\
\hline Mango kernel & $31.92 \pm 0.16_{c}{ }^{a}$ & $34.45 \pm 0.89_{\mathrm{d}}^{\mathrm{a}}$ & $25.23 \pm 1.13_{\mathrm{a}}^{\mathrm{a}}$ & $29.76 \pm 0.71_{\mathrm{b}}{ }^{\mathrm{a}}$ & $47.56 \pm 0.80_{\mathrm{b}}{ }^{\mathrm{a}}$ & $55.43 \pm 1.399^{\mathrm{b}}$ & $43.49 \pm 0.91_{a^{a}}^{a}$ & $51.79 \pm 1.09^{b}{ }^{b}$ \\
\hline
\end{tabular}

Values are mean \pm SD of all samples analyzed individually in triplicate $(P<0.05)$. 
Highest antioxidant potential of pomegranate peels in present study $(75.65 \%)$ was found in agreement with apple peel $(78 \%)^{28}$ but was lower than that reported for pomegranate peel $^{20}$.

Inhibition (\%) of linoleic acid peroxidation of different agro wastes: Selected agro wastes extracts were also assessed for their antioxidant potential by their potential to inhibit peroxidation in linoleic acid system using thyocyanate method $^{16}$. Table-3 revealed appreciable range of inhibition of peroxidation from 43.23 to $82.34 \%$. In general methanolic extracts exhibited a higher level of inhibition of peroxidation than the other solvent extracts. A significant difference was also observed among degree of \% inhibition presented by different agro wastes. Methanolic extracts of pomegranate peels $(82.34 \%)$, citrus leaves $(76.21 \%)$ and citrus peels $(73.81 \%)$, were found to be more effective to inhibit peroxidation than the garlic leaves $(67.04 \%)$, mango peel $(62.23 \%)$, onion leaves $(55.13 \%)$ and mango kernel extracts $(47.56 \%)$. This variation in degree of percent inhibition among the different waste extracts can be attributed to the variation in the amount of total phenolics. According to many reports a good correlation was established between total phenols, total flavonoid contents and percent inhibition of peroxidation which represents antioxidant activity ${ }^{16,20}$.

High degree of percent inhibition of linoleic acid in present study was exhibited by pomegranate peels $(82.34 \%)$ and citrus peels $(73.81 \%)$ found to be slightly lower than earlier reported for pomegranate peels and citrus peels $(96.4 \text { and } 86.9 \%)^{20}$. Variation in degree of percent inhibition may be due to the differences in varieties, solvent used and the applied extraction method $^{20}$. According to Robbins ${ }^{22}$, the inhibition of peroxidation of linoleic acid would be due presence of antioxidant compounds such as xanthones, flavans, flavonols, diantrquinones and some other phenolic compounds in extracts.

Reducing power of agro waste extracts: Table- 4 shows the trends of reducing potential of different agro wastes extracts. The reducing power (absorbance at $\lambda=700 \mathrm{~nm}$ ) of tested agro waste extracts varied from $0.342-1.74$ among different solvents at concentration of $10 \mathrm{mg} / \mathrm{mL}$ and followed the order of effectiveness as: pomegranate peels (1.74) (methanolic extract) $>$ citrus leaves (1.20) (methanolic extract) $>$ mango peel (0.994) (ethanolic extract) > citrus peel (0.994) (methanolic extract) $>$ mango kernal $(0.897)$ (ethanolic extract) $>$ garlic leaves $(0.701)$ (methanolic extract) $>$ onion leaves $(0.623)$ (methanolic extract). In our present study, the organic solvent extracts of waste materials with higher level of TPC exhibited good reducing potential. Among the different antioxidant components of a plant reducing potential is mostly associated with the concentration of total phenolics. Many reports reveal that the extracts with greater amount of total phenolicmay exhibit greater reducing potential ${ }^{20,24}$.

In our present work, reducing power of agro wastes were found in close agreement with those noted for four verities of mango $(0.42-1.27)^{32}$ and residues of six fruits $(0.31-1.54)^{33}$ but were found lower than the leaves of Moringa oleifera (2.45) and Aloe barbadensis leaves (2.01) ${ }^{34}$.

Antifungal activity: As methanolic and ethanolic extracts of agro waste showed good antioxidant activity so they were evaluated for antifungal potential against two strains Aspergillus i.e., Aspergillus flavus and Aspergilllus parasiticus (Figs. 1 and 2). In general inhibitory zones of ethanolic extracts against the A. flavus (14-37 mm) and A. parasiticus (14-38 mm) were found to be comparable to those measured by methanolic extracts (12-32 $\mathrm{mm}$ and 11-35 $\mathrm{mm})$, respectively. Statistical analysis showed that there was no significant difference between antifungal potential exhibited by ethanolic and methanolic extracts against the tested fungi A. parasiticus and A. flavus. However, a significant $(\mathrm{P}<0.05)$ variation among antifungal activities of different extracts was detected.

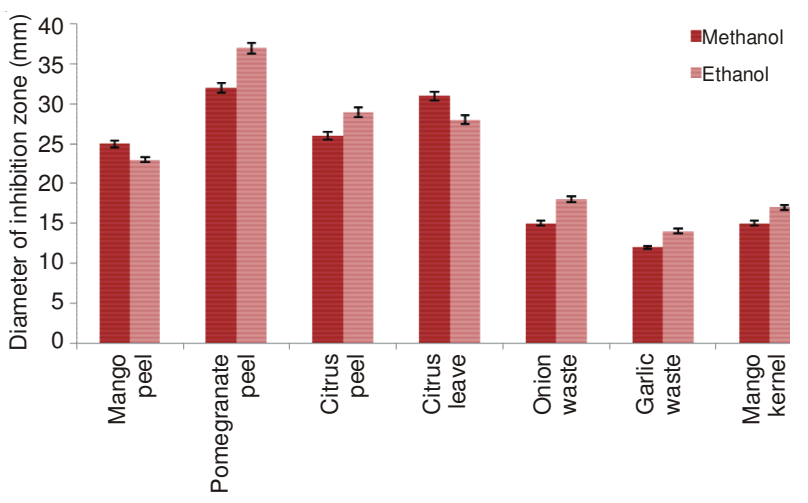

Fig. 1. Antifungal activity of some agro waste against Aspergillus flavus

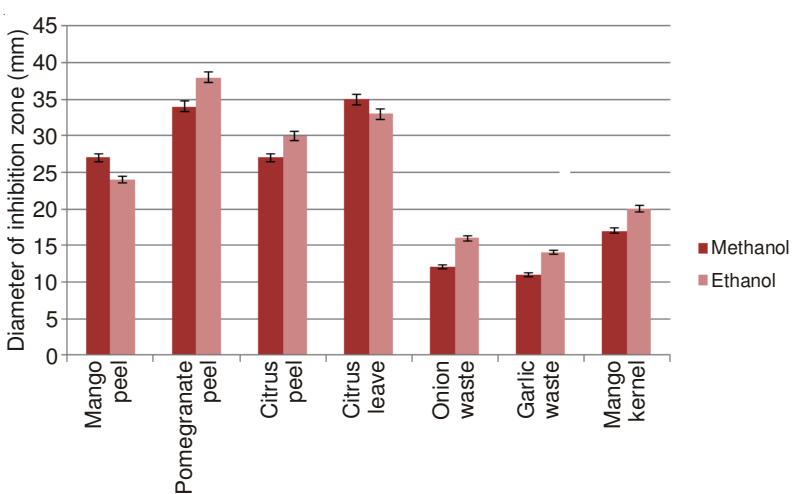

Fig. 2. Antifungal activity of some agro waste against Aspergillus parasiticus

TABLE-4

REDUCING POWER (ABSORBANCE AT $\lambda=700 \mathrm{~nm}$ ) OF VARIOUS AGRO WASTES EXTRACTS

\begin{tabular}{|c|c|c|c|c|}
\hline Plant used & Methanol & Ethanol & Chloroform & Acetone \\
\hline Mango peel & $0.852 \pm 0.02_{c}^{\mathrm{b}}$ & $0.994 \pm 0.03_{\mathrm{d}}^{\mathrm{b}}$ & $0.599 \pm 0.01_{\mathrm{a}}^{\mathrm{b}}$ & $0.732 \pm 0.02{ }^{c}$ \\
\hline Pomegranate peel & $1.740 \pm 0.04_{\mathrm{d}}^{\mathrm{d}}$ & $1.590 \pm 0.03_{\mathrm{c}}^{\mathrm{d}}$ & $1.040 \pm 0.02^{\mathrm{c}}{ }^{\mathrm{c}}$ & $1.290 \pm 0.03_{\mathrm{b}}{ }^{\mathrm{d}}$ \\
\hline Citrus peel & $0.993 \pm 0.03_{\mathrm{d}}^{\mathrm{b}}$ & $0.754 \pm 0.02_{c}^{\mathrm{a}}$ & $0.521 \pm 0.01_{\mathrm{a}}^{\mathrm{b}}$ & $0.621 \pm 0.02_{\mathrm{b}}{ }^{\mathrm{b}}$ \\
\hline Citrus leaves & $1.200 \pm 0.02{ }_{\mathrm{d}}^{\mathrm{c}}$ & $1.080 \pm 0.01_{\mathrm{c}}^{\mathrm{b}}$ & $0.723 \pm 0.02^{\mathrm{b}}$ & $0.943 \pm 0.03_{\mathrm{b}}{ }^{\mathrm{c}}$ \\
\hline Onion leaves & $0.623 \pm 0.01_{\mathrm{d}}^{\mathrm{a}}$ & $0.521 \pm 0.02_{\mathrm{c}}{ }^{\mathrm{a}}$ & $0.342 \pm 0.01_{\mathrm{a}}^{\mathrm{a}}$ & $0.421 \pm 0.01_{\mathrm{b}}{ }^{\mathrm{a}}$ \\
\hline Garlic leaves & $0.701 \pm 0.02_{\mathrm{d}}^{\mathrm{a}}$ & $0.687 \pm 0.01_{d}^{a}$ & $0.343 \pm 0.01_{\mathrm{a}}^{\mathrm{a}}$ & $0.519 \pm 0.01_{\mathrm{c}}^{\mathrm{a}}$ \\
\hline Mango kernel & $0.699 \pm 0.02_{\mathrm{b}}{ }^{\mathrm{a}}$ & $0.897 \pm 0.05_{\mathrm{d}}{ }^{\mathrm{b}}$ & $0.543 \pm 0.01_{\mathrm{a}}^{\mathrm{b}}$ & $0.601 \pm 0.03_{\mathrm{b}}^{\mathrm{b}}$ \\
\hline
\end{tabular}

Values are mean \pm SD of all samples analyzed individually in triplicate $(P<0.05)$. 
The data showed that highest inhibitory effect was exhibited by ethanolic extracts of pomegranate peels with maximum DIZ value of $37 \mathrm{~mm}$ against $A$. flavus while least was observed by garlic leaves $(14 \mathrm{~mm})$. Where as, citrus peels, citrus leaves and mango peels also showed appreciable effects with DIZ values of 29, 28 and $23 \mathrm{~mm}$, respectively, while onion leaves, mango kernel and garlic leaves extracts exhibited a moderate effect with DIZs values of 18,17 and $143 \mathrm{~mm}$, respectively. On the other hand for A. parasiticus pomegranate peels, citrus leaves and citrus peels showed excellent inhibitory effect with DIZs values 38, 33 and $30 \mathrm{~mm}$, respectively, mango peel and mango kernel exhibited moderate inhibitory effect of 24 and $20 \mathrm{~mm}$ and least inhibitory effect was shown by onion and garlic leaves.

In case of methanolic extracts the highest inhibitory effect was presented by pomegranate peels $(32 \mathrm{~mm})$ while garlic leaves showed lowest $(12 \mathrm{~mm})$ inhibitory potential against A. flavus. Citrus leaves, citrus peels and mango peels also presented appreciable inhibitory potential with DIZs values 31,26 and $25 \mathrm{~mm}$. Where as, for A. parasiticus highest inhibitory zone was measured by citrus leaves $(35 \mathrm{~mm})$ followed by pomegranate peels (34 mm), citrus peel (27 mm), mango peel (27 mm), mango kernel (17 mm), onion leaves $(12 \mathrm{~mm})$ and garlic leaves $(11 \mathrm{~mm})$.

Antifungal potential of agro wastes extracts was also assessed by determing their MICs. Various agro waste extracts showed a range of MICs values from 135 to $1340 \mathrm{mg} / \mathrm{mL}$ against $A$. flavus and 99 to $1407 \mathrm{mg} / \mathrm{mL}$ against $A$. parasiticus (Table-5). It was found that citrus leaves (methanolic extract) were most effective with lowest MIC value of $99 \mathrm{mg} / \mathrm{mL}$ against $A$. parasiticus and garlic leaves extract were least effective with highest MIC value of $1407 \mathrm{mg} / \mathrm{mL}$. On the other hand pomegranate peels (ethanolic extract) were found most effective for A. flavus than other extracts with lowest MIC value of $135 \mathrm{mg} / \mathrm{mL}$.

The remarkable inhibitory effect of citrus leaves and pomegranate peels (MIC value 99 and $107 \mathrm{mg} / \mathrm{mL}$ ) as observed against $A$. parasiticus was found to be noticeably lower than that noticed for gold mohar leaves and flowers ( 45 and $65 \mathrm{mg}$ / $\mathrm{mL}$ ) against $A$. nigar ${ }^{29}$. Although the antifungal potential of citrus leaves, mango peel and citrus peels observed in present analysis for A. flavus and A. parasiticus was found to be relatively greater than those measured for onion bulb $(17.3 \mathrm{~mm})$, scallion $(12.6 \mathrm{~mm})$ against $A$. niger and singara rind $(15 \mathrm{~mm})$ against A. flavus but were comparable to pomegranate rind $(23 \mathrm{~mm})$ and bakeri garlic $(22 \mathrm{~mm})^{35}$.

According to our findings highest inhibitory potential of pomegranate peels extract against $A$. parasiticus and $A$. flavus was found to be comparable with the earlier report of Orak et al..$^{36}$ who also noticed extraordinary inhibitory effect for different genotypes of pomegranate peels against A. parasiticus. According to Reddy et al. ${ }^{37}$ report antifungal activity of pomegranate may be attributed to the presence of ellagic acid and punicalagins in pomegranate juice byproducts. However, a comparison among efficiencies exhibited by different waste extracts against two fungal species showed that $A$. parasiticus was resistant greater than A. flavus. This might be due to the effects that antifungal compounds or antifungal modes are not identical for different Aspergillus species.

Phenolic acids: In present analysis remarkable high antioxidant and antifungal activity of investigated leaves and peels against the tested fungi might be due to the existence of flavonoids and phenolic acids like gallic acid, cholorogenic acid, caffeic acid, 3-hydroxybenzoic acid and protocatechuic acid ${ }^{38}$. So the extracts which exhibited remarkable antifungal and antioxidant activities were further evaluated for their phenolic acid profile by GC/MS technique.

The analysis of agro waste revealed that total of 7 phenolic acids like gallic acid, vanillic acid, cinamic acid, protocacheuic acid, caffeic acid, ferulic acid and $p$-coumaric acid were identified on the basis of availability of standard chemicals and spectral data (Table-6). A significant variation $(\mathrm{P}<0.05)$ was detected in concentration of phenolic acids among different wastes. Gallic acid was detected in almost all waste

\begin{tabular}{|c|c|c|c|c|}
\hline \multirow{3}{*}{ Plant used } & \multicolumn{4}{|c|}{$\begin{array}{c}\text { TABLE-5 } \\
\text { MINIMUM INHIBITORY CONCENTRATION OF METHANOL AND ETHANOL } \\
\text { EXTRACTS AGAINST Aspergillus flavus AND Aspergillus parasiticus }\end{array}$} \\
\hline & \multicolumn{2}{|c|}{ Aspergillus flavus } & \multicolumn{2}{|c|}{ Aspergillus parasiticus } \\
\hline & Methanol & Ethanol & Methanol & Ethanol \\
\hline Mango peel & $415 \pm 9.98_{\mathrm{c}}^{\mathrm{a}}$ & $480 \pm 8.11_{\mathrm{d}}^{\mathrm{b}}$ & $325 \pm 7.23_{\mathrm{a}}{ }^{\mathrm{a}}$ & $452 \pm 9.01_{c}^{\mathrm{b}}$ \\
\hline Pomegranate peel & $185 \pm 3.74_{d}{ }^{a}$ & $135 \pm 3.75_{\mathrm{b}}{ }^{\mathrm{a}}$ & $149 \pm 4.78_{c}{ }^{a}$ & $107 \pm 2.76_{\mathrm{a}}{ }^{\mathrm{a}}$ \\
\hline Citrus peel & $387 \pm 7.32_{\mathrm{d}}^{\mathrm{a}}$ & $342 \pm 7.21_{\mathrm{c}}^{\mathrm{a}}$ & $310 \pm 7.56_{c}{ }^{a}$ & $216 \pm 5.43_{a^{a}}{ }^{a}$ \\
\hline Citrus leaves & $290 \pm 5.91_{\mathrm{b}}^{\mathrm{a}}$ & $721 \pm 14.70_{d}^{b}$ & $99 \pm 19.80_{a}^{a}$ & $160 \pm 4.78_{a^{a}}$ \\
\hline Onion leaves & $953 \pm 19.70_{\mathrm{b}}^{\mathrm{c}}$ & $759 \pm 16.60_{a}^{c}$ & $1295 \pm 25.4_{d}{ }^{d}$ & $981 \pm 19.80_{\mathrm{b}}{ }^{\mathrm{d}}$ \\
\hline Garlic leaves & $1340 \pm 27.50_{c}{ }^{d}$ & $1190 \pm 24.40_{\mathrm{a}}^{\mathrm{d}}$ & $1407 \pm 29.70_{d}^{d}$ & $1235 \pm 25.60_{\mathrm{a}}^{\mathrm{d}}$ \\
\hline Mango kernel & $953 \pm 18.90_{\mathrm{d}}^{\mathrm{c}}$ & $868 \pm 17.60_{\mathrm{d}^{\mathrm{c}}}^{\mathrm{c}}$ & $835 \pm 17.4_{d}{ }^{c}$ & $465 \pm 9.67_{\mathrm{a}}^{\mathrm{b}}$ \\
\hline
\end{tabular}

TABLE-6

CONTENTS OF PHENOLIC ACIDS (mg/g OF DRY MATTER) OF SOME AGRO WASTES QUANTIFIED BY GC-MS

\begin{tabular}{lccccccc}
\hline & $\begin{array}{c}\text { Gallic } \\
\text { acid }\end{array}$ & $\begin{array}{c}\text { Cinamic } \\
\text { acid }\end{array}$ & $\begin{array}{c}\text { Vanalic } \\
\text { acid }\end{array}$ & $\begin{array}{c}\text { Protocacheuic } \\
\text { acid }\end{array}$ & $\begin{array}{c}\text { Ferulic } \\
\text { acid }\end{array}$ & $\begin{array}{c}\text { Caffeic } \\
\text { acid }\end{array}$ & $\begin{array}{c}\text { P-Coumaric } \\
\text { acid }\end{array}$ \\
\hline Mango peel & $1.89 \pm 0.40$ & ND & ND & $0.26 \pm 0.04$ & ND & $0.17 \pm 0.02$ & $0.04 \pm 0.01$ \\
Citrus peel & $2.25 \pm 0.75$ & $0.11 \pm 0.01$ & ND & $0.14 \pm 0.03$ & ND & $1.17 \pm 0.20$ & $0.01 \pm 0.00$ \\
Pomegranate peel & $6.11 \pm 0.92$ & $0.21 \pm 0.05$ & $0.26 \pm 0.04$ & ND & $0.12 \pm 0.02$ & ND & $0.43 \pm 0.07$ \\
Citrus leaves & $0.96 \pm 0.03$ & ND & $0.81 \pm 0.02$ & $0.03 \pm 0.007$ & ND & $0.17 \pm 0.02$ & $0.08 \pm 0.00$ \\
\hline Van
\end{tabular}

Values are mean \pm SD of three separate experiments. 
extracts in significant $(\mathrm{P}<0.05)$ higher amount ranging from 0.96 to $6.11 \mathrm{mg} / \mathrm{g}$ of dry matter followed by $p$-coumaric acid ( 0.01 to $0.43 \mathrm{mg} / \mathrm{g}$ dry matter) and caffeic acid (0.07 to 1.17 $\mathrm{mg} / \mathrm{g}$ of dry matter) whereas cinamic, protocatechuic and vanillic acids were found in few of extracts in small amount ranging from $0.11-0.21,0.03-0.26$ and $0.26-0.81 \mathrm{mg} / \mathrm{g}$ of dry matter, respectively and ferulic acid was detected at a small level $0.012 \mathrm{mg} / \mathrm{g}$ of dry matter only in pomegranate peels.

Among the peels of different fruits as investigated in present analysis, pomegranate peels were found to be richest in gallic acid and $p$-coumaric acid at concentration of 6.11 and $0.43 \mathrm{mg} / \mathrm{g}$ following vanillic acid $(0.26 \mathrm{mg} / \mathrm{g})$, cinamic acid $(0.21 \mathrm{mg} / \mathrm{g})$ and ferulic acids $(0.12 \mathrm{mg} / \mathrm{g})$. Elango et al..$^{39}$ reported the presence of gallic and ellagic acid in pomegranate peel determined by GC-MS but they did not report the presence of other acids in their study that were detected in present work i.e., $p$-coumaric acids, vanillic, cinamic and ferulic acids. Citrus peels were also found to contain highest amount of gallic acid $(2.25 \mathrm{mg} / \mathrm{g})$ and caffeic acid $(1.17 \mathrm{mg} / \mathrm{g})$, followed by protocatechuic acid $(0.14 \mathrm{mg} / \mathrm{g})$ and small amount of $p$-coumaric acids $(0.01 \mathrm{mg} / \mathrm{g})$. Citrus leaves also contained all those acids that were detected in peels except cinamic acid but their concentration in leaves was found quite lower than peels. Mango peels were also found to contain appreciable amounts of gallic acid, protocacheuic acid, caffeic acid, $p$-coumaric and at levels of 1.89, 0.260 .17 and $0.04 \mathrm{mg} / \mathrm{g}$, respectively.

However, there are numerous differences among the phenolic acids profile found in the present work and those reported earlier. These differences may be accredited to the differences in plant habitat, methodology of sample preparation and analysis. So it is necessary to use various analytical techniques to determine plant metabolites ${ }^{40}$. It was found that wastes showed high contents of phenolic acids also displayed potent antioxidant as well as antifungal activities. A good correlation exists between phenolic compounds and antifungal activity which is in agreement with the findings of Martin et al. ${ }^{1}$.

\section{Conclusion}

In conclusion, the ethanolic and methanolic extracts of different agricultural wastes have demonstrated a broad spectrum of antioxidant and antifungal activities against tested fungi. Gas chromatography mass spectrometry analysis showed the presence of various phenolic acids with variable concentration. On the basis of the results, it would be possible to use waste extracts to formulate new products as food preservatives to be used in food industry replacing synthetic antioxidants and antifungal agents.

\section{ACKNOWLEDGEMENTS}

The authors are grateful to the Higher Education Commission for providing financial support under the project "Protection of cereal grains against aflatoxin contamination using plant materials".

\section{REFERENCES}

1. J.G.P. Martin, E. Porto, C.B. Corrêa, S.M. de Alencar, E.M. da Gloria, I.S. Ribeiro Cabral and L.M. de Aquino, J. Nat. Prod., 5, 27 (2012).

2. J. Dai and R.J. Mumper, Mol., 15, 7313 (2010).
3. C. Ajila, L. Jaganmohan Rao and U.J.S. Prasada Rao, Food Chem. Toxicol., 48, 3406 (2010).

4. S.S.T. Hua, O.K. Grosjean and J.L. Baker, Lett. Appl. Microbiol., 29, 289 (1999).

5. M. Razzaghi-Abyaneh, M. Shams-Ghahfarokhi, T. Yoshinari, M.-B. Rezaee, K. Jaimand, H. Nagasawa and S. Sakuda, Int. J. Food Microbiol., 123, 228 (2008).

6. J.H. Kim, B.C. Campbell, J. Yu, N. Mahoney, K.L. Chan, R.J. Molyneux, D. Bhatnagar and T.E. Cleveland, Appl. Microbiol. Biotechnol, 67, 807 (2005).

7. S. Abou-Bakr, Int. J. Acad. Res, 3, 116 (2011).

8. S. Mahmud, M. Saleem, S. Siddique, R. Ahmed, R. Khanum and Z. Perveen, J. Saudi Chem. Soc., 13, 195 (2009).

9. N.S. Al-Zoreky, Int. J. Food Microbiol., 134, 244 (2009).

10. J.D. Adamez, E.G. Samino, E.V. Sanchez and D. Gonzalez-Gomez, Food Contr., 24, 136 (2012).

11. F.A. Tomas-Barberan and J.C. Espin, J. Sci. Food Agric., 81, 853 (2001).

12. N. Balasundram, K. Sundram and S. Samman, Food Chem., 99, 191 (2006).

13. A. Chaovanalikit and R.E. Wrolstad, Food Chem. Toxicol., 69, 67 (2004).

14. V. Dewanto, X. Wu, K.K. Adom and R.H. Liu, Agric. Food Chem, 50, 3010 (2002).

15. S. Iqbal, M.I. Bhanger and F. Anwar, Food Chem., 93, 265 (2005).

16. G.C. Yen, P.D. Duh and D.Y. Chung, Food Chem., 70, 437 (2000).

17. Clinical and Laboratory Standards Institute, M44-A, Clinical and Laboratory Standards Institute, Wayne, PA (2004).

18. S.B. Misra and S.N. Dixit, Experientia, 34, 1442 (1978).

19. O. Tokusoglu, M.K. Unal and Z. Yildirum, Acta Chromatogr., 13, 196 (2003).

20. B. Sultana and F. Anwar, Grasay Y Aceites., 59, 205 (2008).

21. B. Hsu, I.M. Coupar and K. Ng, Food Chem., 98, 317 (2006).

22. R.J. Robbins, J. Agric. Food Chem., 51, 2866 (2003).

23. D. Huang, B. Ou and R.L. Prior, J. Agric. Food Chem., 53, 1841 (2005).

24. P. Siddhuraju and K. Becker, J. Agric. Food Chem., 51, 2144 (2003).

25. Y. Li, C. Guo, J. Yang, J. Wei, J. Xu and S. Cheng, Food Chem., 96, 254 (2006)

26. S.R. Kanatt, R. Chander and A. Sharma, Int. J. Food Sci. Technol., 45, 216 (2010).

27. K. Ghasemi, Y. Ghasemi and M.A. Ebrahimzadeh, Pak. J. Pharm. Sci., 22, 277 (2009).

28. B. Dabrosca, S. Pacifico, G. Cefarelli, C. Mastellone and A. Fiorentino, Food Chem., 104, 1333 (2007).

29. G. Shabir, F. Anwar, B. Sultana, Z.M. Khalid, M. Afzal, Q.M. Khan and M. Ashrafuzzaman, Molecules, 16, 7302 (2011).

30. A.K. Ghimeray, C. Jin, B.K. Ghimire and D.H. Cho, Afr. J. Biotechnol., 8, 3084 (2009).

31. M. Öztürk, F. Aydogmus-Öztürk, M.E. Duru and G. Topçu, Food Chem., 103, 623 (2007).

32. S.M.R. Ribeiro, L.C.A. Barbosa, J.H. Queiroz, M. Knödler and A. Schieber, Food Chem., 110, 620 (2008).

33. N. Babbar, H.S. Oberoi, D.S. Uppal and R.T. Patil, Food Res. Int., 44, 391 (2011).

34. B. Sultana, F. Anwar and M. Ashraf, Molecules, 14, 2167 (2009).

35. S.S. Dahham, M.N. Ali, H. Tabassum and M. Khan, Am. Eur. J. Agric. Env. Sci, 9, 273 (2010).

36. H.H. Orak, A.S. Demirci and T. Gumus, Elec. J. Environ. Agric. Food Chem., 10, 1958 (2011).

37. M.K. Reddy, S.K. Gupta, M.R. Jacob, S.I. Khan and D. Ferreira, Planta Med., 73, 461 (2007).

38. L.S. Kasim, V.A. Ferro, O.A. Odukoya, G.E. Ukpo, V. Seidel, A.I. Gray and R. Waigh, J. Med. Plants Res., 5, 862 (2011).

39. S. Elango, R. Balwas and V.P. Viswanadha, J. Canc. Therap., 2, 638 (2011).

40. J. Rzepa, M. Sajewicz, T. Baj, P. Gorczyca, M. W odarek, S. Kwiatkowski, T. Kowalska and M. Waksmundzka-Hajnos, Annales UMCS, Sectio DDD Pharmacia, 24, 49 (2011). 